\title{
DOES THE FINANCIAL MARKET LEAD THE BUSINESS CYCLE IN SOUTH AFRICA?
}

\author{
Ilsé Botha \\ University of Johannesburg, South Africa \\ ilseb@uj.ac.za
}

November 2007

\begin{abstract}
Financial markets play a significant role in an emerging market economy such as South Africa, especially after financial liberalisation. Financial liberalisation causes economies to interrelate across borders and between different sectors. The impact of this interrelationship can be captured by taking the different components of the financial market into account and relating these to the real sector, using the coincident indicator. It will be useful to identify an indicator representing the major components - equity market, capital market and the domestic financial sector - of the financial market in South Africa. This financial indicator will lead the coincident indicator, because the components of the financial indicator are available at a higher frequency than the components of the coincident indicator. This new indicator for South Africa will be of assistance in making more informed business decisions since it can be used to forecast turning points in the coincident indicator, i.e. the business cycle.
\end{abstract}

\section{Keywords:}

Financial liberalisation; financial indicator; leading indicator; real business cycle; emerging financial markets; developed markets 


\section{INTRODUCTION}

Economic fluctuations are analysed in terms of business-cycle phases. There are official classifications of the business cycle. No similar interest has flourished in characterising boombust cycles in financial markets. The reason for the lack of interest might stem from the notion that, in efficient markets, prices should follow a random walk process. In this case cycles are meaningless. But in 1990, Cechetti, Lam and Mark showed that even in efficient markets stock prices can follow mean reverting processes, with cycles in the stock market replicating cycles in output (Kaminsky \& Schmukler, 2001).

Business cycle theories usually concentrate on the real sector of the economy. The financial sector is a very important role player in a country's well being, especially since the advent of globalisation. Therefore these two sectors are interlinked with each other. The business cycle indicators published by the South African Reserve Bank (SARB) are available with a time lag and it is for this reason that it might be useful to use financial indicators to predict the turning points in the business cycle indicators since financial data is available at a higher frequency than most real sector data.

This paper uses the components of financial liberalisation - the domestic financial sector, the capital market and the stock market - to form a financial indicator which leads or coincides with the coincident indicator of the SARB.

This paper is organised as follows: in section 2 various methods of measuring the business cycle are discussed and section 3 will follow with a discussion on the measurement of the South African business cycle, because the financial indicator will be compared to the coincident indicator, representing the business cycle. In section 4 there will be a brief discussion on the components of financial liberalisation to motivate the use of the said financial indicators for the composite financial indicator. In section 5 this financial indicator for South Africa will be constructed and section 6 will conclude the article.

\section{BUSINESS CYCLE MEASUREMENT}

Business cycle theory can only have relevance if there is indeed some empirical evidence of cyclic performance. There is a lively interest in the business cycle, not only among economists, but also among business people and ordinary citizens. The question is regularly asked whether the economic conditions are improving or worsening. The question is where the economy is in the business cycle. Private sector economists devote a vast amount of time and effort to answering this type of question. There is a problem: information about the performance of the economy as a whole only becomes available weeks, even months, after the events have occurred. To overcome this problem certain critical variables or indicators that possibly reflect or predict movements in overall economic activity have been identified. These variables are called business cycle indicators. The most important indicators are called the leading indicators, which tend to peak before the peak in aggregate economic activity and reach a trough before the trough in aggregate economic activity. To establish which indicators are leading indicators, the movements of different variables in relation to overall changes of economic activity are examined. Economies change and develop and an indicator system which captures changes in a given economy in a particular era in a reasonably satisfactory way cannot be counted on to 
continue to do so indefinitely.

The basic underlying notion, a Mitchellian notion, is that business cycles reflect recurring if complicated dynamic interrelationships among significant variables and they experience pressures emanating from cyclical instability. This view is still sound, according to Klein (1997) as is the notion that timing relationships among indicators are fairly consistent (leaders do not become laggers). When one is striving to capture the most significant forces through which the cycle manifests itself, it is necessary to constantly reassess aggregate economic performance in an effort to capture changing sector importance.

In 1946, Wesley Mitchell and Arthur Burns developed a method specifically for measuring the business cycle (Sherman \& Kolk, 1996). The method begins by establishing the trough and peak dates of each cycle, using all available evidence. This dating method was adopted by the NBER. They pointed out that the best statistics to use in cycle analysis are quarterly data. Statistics on a daily, weekly or monthly basis tend to contain too much static. Annual data distorts many cyclical turning points because turning points are often in the middle of the year and are not sufficiently detailed (Sherman \& Kolk, 1996). A cycle may be measured from trough to trough or from peak to peak. The business cycle as defined by Mitchell has four phases, starting at the initial trough of the cycle: there is a rapid upturn, called the recovery; then there is an expansion, called prosperity; this is followed by a downturn, a crisis; this crisis turns into a contraction called a depression (Sherman \& Kolk, 1996).

\subsection{Methods of measurement}

The more or less regular movement of numerous economic entities is accepted as a fact by most economists; however, measuring the aggregate state of the economy with regard to these business fluctuations is difficult due to the many single economic magnitudes involved. While some economic activities are expanding at a point in time, others have already reached their upper turning point and still others are on the downswing; a few economic activities might even be at a lower turning point. At the core of the discussion on measuring the current business activities are two concepts: the use of economic indicators and the concept of potential economic output.

\subsubsection{Economic indicators}

This method's basic idea consists of constructing different time series data so that the overall movement of economic activities is made transparent by these series.

The Harvard Barometer was developed by WM Pearson in 1919 and originally consisted of five groups of time series (Gabisch \& Lorenz, 1989). Time series belonging to the same group were characterised by roughly similar and simultaneous cycles. In order to give a clearer picture of the cyclical movements of general business activities, the five groups were later reduced to three: the $A B C$ groups - hence the name Harvard-ABC. Group A represented speculation, group $B$ physical productivity and commodity prices, and group $C$ the financial situation in New York. This barometer was not only used to measure past and present business cycles, but was also intended to serve as an instrument to predict business cycles.

Pearson stated "... the sort of measure desired is one that is not applicable merely to past data but that can be applied with some confidence to the present and the future" (Gabisch \& Lorenz, 1989). This indicator was totally abandoned as predictions became unreliable - especially after the indicator failed to predict the great depression. 
Mitchell and Burns developed the basic idea of the reference cycle in 1938. They examined 487 statistical series and ended up by choosing 71 time series as statistical indexes of cyclical revivals. These series were ordered according to the average lead or lag. The idea of leading, lagging and coinciding series was developed even further by Moore in 1950. In his study he included 801 monthly and quarterly time series for the US. From these series he chose economic indicators that passed a test for conformity and timing - conformity meaning the consistency with which the series conformed to business cycles, and timing referring to the consistency with which a time series' turning point led, lagged or coincided with the reference data. Thus, 225 out of the 801 series were chosen and were condensed into five groups characterised by long leads, short leads, short lags and long lags (Gabisch \& Lorenz, 1989). This classification was finally reduced to 21 . These were divided into leading, lagging and roughly coinciding groups. Moore was confident in its forecasting ability; however, it did not prove its forecast accuracy.

Another indicator developed by the NBER was the diffusion index. The concept of this index is rather simple: at any point in time some series out of a specified set may move upwards while the rest are moving downwards. If the relative number of upward-moving series is greater/less than 0,5 the economy is expanding/contracting. Burns and Moore in 1954 applied this idea systematically to different sets of economic time series and called the proportion of expanding series the "diffusion index". According to Moore this was the best historical index of the cyclical position the US economy ever had. When this method of constructing a diffusion index is applied to historical data the cyclical turns of the aggregate are preceded by the turns of the diffusion index (Gabisch \& Lorenz, 1989).

\subsubsection{Capacity utilisation}

Fluctuating employment rates after the Second World War (WWII) became a prominent feature of business cycles. Because of this the business cycle phenomenon has increasingly been considered with respect to how the employment rate is affected during the business cycle and to what extent the stabilisation policy has succeeded in keeping employment at a high level. Thus employment itself or closely related economic magnitudes are sometimes used as a measure of the business cycle. Among these magnitudes are the gross national product and its rate of change. The interrelationship between the GNP and employment is interpreted in the Keynesian spirit. If capacities are under-utilised, a growing GNP must be accompanied by growing employment. Hence, as much as one stresses the importance of growing employment during an expansion, it suffices only to measure the rate of change in GNP. This view only takes into account what actually happened, and ignores what might have happened. Thus measuring GNP does not say anything about what GNP could have been if all productive resources, including labour, had been fully utilised. This brings us to the concept of 'potential GNP', which would be produced by the full employment of all factors of production - as compared to actual GNP, which is produced by the actual employment of the factors of production.

The simpler concepts of measuring the rate of capacity utilisation take into account just one production factor. This factor is either labour or capital. The production function can also link the actual GNP $y(t)$ to the input of actual factors of production - labour $L(t)$ and capital $K(t)$

$$
y_{(t)}=f\left(L_{(t)}, K_{(t)}\right)
$$

The potential GNP can be linked to potential capital and labour

$$
y_{p_{(t)}}=f p\left(L p_{(t)}, K p_{(t)}\right)
$$


Klein developed the Wharton School index in 1964, the main advantage of which is its simplicity (Gabisch \& Lorenz, 1989). The last cyclical peaks of a relevant economic time series are linearly connected. The line passing through these points is interpreted as the capacity line. It follows that the ratio between actual and potential GNP as indicated by the capacity line represents the rate of capacity utilisation. Critics had one main objection to this method and that is that at a cyclical peak the available capacity is not necessarily fully utilised. A cyclical peak is nothing but a local maximum in for example production, and leaves the question open whether the economy works with full capacity utilisation or not.

Another way of estimating capacity utilisation is to survey businesses directly. There are two types of surveys. The first is to determine at what percentage rate of capacity a company is operating at a given moment. Different answers are used to calculate the rate of capacity utilisation for a particular industry.

The second survey type estimates only the percentage rate of businesses operating at full capacity. Putting this question to companies renders only a yes or no answer, which make this type of survey unreliable and less information-yielding than the first (Gabisch \& Lorenz, 1989).

\section{MEASURING THE BUSINESS CYCLE IN SOUTH AFRICA}

The South African Reserve Bank has identified the turning points in the South African business cycle since 1946, and first published composite business cycle indicators in 1983. Methods of determining the turning points combine several techniques (Pretorius, Venter \& Weideman, 1999).

Firstly, the composite and coincident business cycle indicators are calculated. The composite indicator is a weighted average of economic indicators that antecedes economic activity in the past. Similarly, the coincident indicator is the weighted average of the economic indicators which coincided with the business cycle.

TABLE 1: Component time series of the composite coincident business cycle indicator in SA

Component time series

Gross value added at constant prices, excluding agriculture, forestry and fishing

Value of wholesale, retail and new vehicle sales at constant prices

Utilisation of production capacity in manufacturing

Total formal non-agricultural employment

Industrial production index

Source: South African Reserve Bank, Quarterly Bulletin (March 2004)

Secondly, the comprehensive composite index is calculated (this is also referred to as the current diffusion index, used by the NBER). This is compiled by the actual month-on-month percentage change in 251 economic time series, which cover economic processes such as production, demand, employment and income in different sectors of the economy. These indicators are weighted according to their contribution to value-added. As these weights might change over time, the weight assigned to a specific sector is determined as the average of the 
relative contribution of that sector to the total value of production for different sub-periods. The deviation of the current diffusion index from its long-term trend is a quantitative indication of the cyclical movement in general economic activity (Pretorius \& Venter, 2001).

Thirdly, the same 251 time series are used to calculate the historical diffusion index, which can be defined as the measure of dispersion of the changes in a number of time series during any particular period. The weighting of this index is the same as for the current diffusion index. The turning point of each series is determined. The value of the historical diffusion index is determined by expressing the time series, which increase during a certain period as a percentage of the total time series under consideration. An index value of below 50 indicates that more than half of the series are decreasing at a particular date, implying the economy is in a downward phase (Pretorius \& Venter, 2001). This is not purely mechanical and certain economic developments are also taken into consideration during the time of the turning point in order to get the exact date of the turning point.

Various factors, such as structural changes in the economy or the identification of new economic indicators, necessitate the frequent reassessment of the constituent time series of the composite business cycle indicators. The SARB's three composite business cycle indicators were last revised in 1994. Since 1994 important structural changes have occurred in South Africa, both politically and economically (Pretorius \& Venter, 2001).

During the 1990s it became apparent that some of the component time series of the composite leading business cycle indicator no longer reliably predicted movements in the business cycle. This was due to policies implemented since 1994 by South Africa's first democratically elected government. These include, among other things, the removal of many trade restrictions between South Africa and the rest of the world and the gradual liberalisation of exchange controls.

It is because of this that it might be useful to use the information in the financial markets to predict turning points in the business cycle. The coincident indicator for South Africa will be used as the reference cycle to construct the financial indicator for South Africa. The construction of the financial indicator is different from, and simpler than, the construction of the composite business cycle indicators discussed above. The reasons for this are that more research is needed to have the likes of 250 and more time series to use and the purpose of this financial indicator is to create a simple tool to help with the decision making process.

\section{COMPONENTS OF FINANCIAL LIBERALISATION}

Macroeconomic and financial volatility is a well-known downside of financial liberalisation. South Africa was excluded from mainstream global economic developments from 1960 to 1994. Following the political and social reforms of 1994, the new South African government pursued a policy of re-integrating the country into the world economy, and of participating in the process of economic globalisation. Policy measures taken to achieve this objective included, firstly, the relaxation of exchange controls. Secondly, significant reductions in restrictive tariffs on international trade were also used. Thirdly, major reforms in the banking and financial sectors (bank regulation and supervision based on internationally accepted principles, restructuring of the Johannesburg securities exchange (JSE) in South Africa and liberalisation of the money and capital markets). Finally, new bilateral and multilateral economic agreements with other countries were used (Stals, 2002).

After the emerging market financial crises of the 1990s and early 2000 s - which claimed a good 
number of emerging market economies as their victims - this characteristic of financial market liberalisation acquired a new significance (Das, 2003). Due to this significance, three components of liberalisation have been identified, i.e. capital account liberalisation, liberalisation in the equity markets and liberalisation of the domestic financial markets.

\subsection{Capital account liberalisation}

Kaminsky and Reinhart (1999) have established a link between financial liberalisation and economic, financial and balance-of-payments crises. All of these crises are traumatic and have high economic and social costs. The individual emerging market economies suffered as much as the global economy. Problems in the banking sector precede a currency crisis, the currency crisis deepens the banking crisis and a spiral starts. Financial liberalisation usually precedes a banking crisis. A crisis occurs as the economy enters a recession, following a prolonged boom in economic activity that was fuelled by credit, capital flows and accompanied by an overvalued currency (Kaminsky \& Reinhart, 1999). A shock to the financial system, such as financial liberalisation, can result in a boom.

The growing globalisation of capital markets and declining transaction costs can make global investors rationally "exuberant". In such an environment, information asymmetry leads to herding behaviour, which manifests itself in "excesses", or booms and bursts in the international capital markets (Calvo \& Mendoza, 2000).

\subsection{Liberalisation of equity markets}

Edwards, Biscarri, and De Gracia (2003) investigated whether stock markets behave the same in developed and emerging markets.

Kaminsky and Schmukler (2002) took into account the financial crises in emerging and industrial economies, including the crises of the 1990s, before concluding that financial cycles in the equity markets were not intensified by financial liberalisation. If anything, the opposite is true. Equity market cycles become smoother after liberalisation. Interestingly, they found intertemporal differences in the impact of financial liberalisation on the equity market. Liberalisation tended to trigger more explosive financial cycles in the immediate aftermath of financial liberalisation. However, in four years after liberalisation the equity market volatility became markedly less pronounced. This observation applies to both emerging market economies as well as mature industrial economies.

Stock prices have been a business cycle indicator since 1938 (Kaminsky \& Schmukler, 2002). Schwert (1989) studied the relationship between business cycles, financial crisis and stock volatility. Evidence shows that stock volatility increases after stock prices fall, and it increases around major financial crises. Stock market discounts expected future events into current prices. From this perspective, stock prices reflect increased uncertainty about the future course of the economy, which shows up later in the realised growth rates of non-financial macroeconomic variables such as the money supply, consumption and investment. This rational expectations/efficient markets approach implies that time-varying stock volatility (conditional heteroscedasticity) provides important information about future macroeconomic behaviour.

\subsection{Domestic liberalisation}

Distortionary macroeconomic policies and volatility have been found to be closely related. 
Ineffective macroeconomic policies like excessive government spending, high inflation, and over-valued exchange rates render an economy prone to crisis. If regulation and supervision progress hand-in-hand with financial liberalisation, the negative impact of financial liberalisation on the emerging market economy can be harnessed (Das, 2003).

Calvo and Mendoza (2000) are of the opinion that if cyclical changes in interest rates drive the surges of capital flows, then these surges must have a large temporary component. Given the temporariness of capital flows, analysts are likely to wonder if government can ensure a soft landing when flows subside. Thus surging capital flows may breed the expectation of a future policy switch. The credibility of government is a central element of the transmission mechanism linking information-driven capital flows with business cycles in emerging markets.

\section{CONSTRUCTING A FINANCIAL INDICATOR FOR SOUTH AFRICA}

The components of the financial market posited by Kaminsky and Schmukler will be used to construct the financial indicator for South Africa. The three components will be the equity market, the capital market and the domestic financial sector. These three components include the most important liberalisations in order to understand the financial markets as discussed in the previous section.

The proxies for liberalisation in each are the all-share index of the JSE as well as net equity flows for the equity market; $R / \$$ exchange rate, the real effective exchange rate and the balance on the financial account, for the capital market; and the real interest rate spread and $M 3$ for the domestic financial sector. The chosen variables are in line with the suggestions from Kaminsky and Schmukler and the data for the variables is fairly easy to access.

The analysis will be conducted by using simple regression analysis, firstly relating each component to the coincident indicator. The estimate from each component will be jointly related to the coincident indicator and then an index will be formed and compared to the actual coincident indicator.

\subsection{Analysis of the individual components of the financial indicator}

The sample period includes 50 observations on a quarterly basis, and the sample is from the first quarter 1994 to the second quarter 2006. The sample starts at 1994, since the South African market started to liberalise in the early 1990s. Each component of the financial market will be analysed, using simple regression analysis. The dependent variable in each regression is the coincident indicator compiled by the South African Reserve Bank (SARB). The rest of the data was extracted from the SARB database and the I-net Bridge database. The results of each component, i.e. equity market, capital market and the domestic financial market, follow.

\subsubsection{The equity market}

The variables representing the equity market of the financial market were the returns on the allshare index and the net equity flows on the JSE. Both these variables and the dependent variable were I(l) and cointegration was present; therefore the variables were used on the levels.

Both variables were statistically significant (at a $95 \%$ confidence level) and showed a positive relationship with the coincident indicator. Heteroscedasticity was not present, but autocorrelation was and the standard errors were adjusted with Newey-West. The best lag 
structure was chosen according to the Schwarz information criterion (SIC). The adjusted Rsquared implies that $74 \%$ of the variation in the coincident indicator is due to the explanatory variables.

TABLE 2: Regression results for the equity component

\begin{tabular}{lcccc}
\hline $\begin{array}{l}\text { Dependent Variable: COIN } \\
\text { Newey-West HAC Standard Errors \& Covariance }\end{array}$ & (lag truncation=3) & & \\
\multicolumn{1}{c}{ Variable } & Coefficient & Std. Error & t-Statistic & Prob. \\
\hline C & -270.7222 & 64.28498 & -4.211282 & 0.0001 \\
LOG(ALSI(-1)) & 42.69907 & 7.248512 & 5.890735 & 0.0000 \\
FLOWS & $4.83 \varepsilon-07$ & $2.36 \varepsilon-07$ & 2.043229 & 0.0468 \\
R-squared & & & & \\
Adjusted R-squared & 0.748707 & & & \\
\hline
\end{tabular}

Source: Results from Eviews

\section{FIGURE 1: Equity component of the financial indicator}

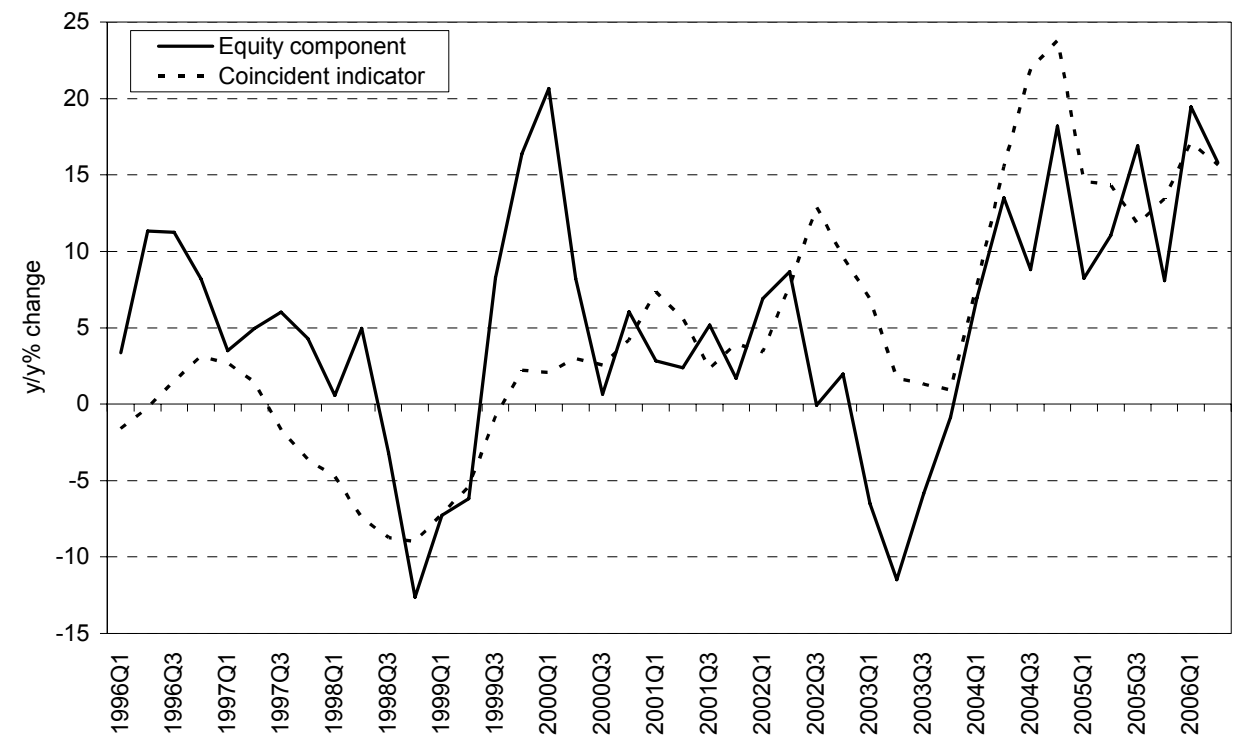

Source: Results from regression model in Eviews

FIGURE 1 shows the estimate from the regression analysis - the equity component. There is a close relationship between the equity component and the coincident indicator, and it seems as if the equity component is leading the coincident indicator at some stages in the sample period. The Granger causality test suggested a one-way flow of causality from the equity component to the coincident indicator. 


\subsubsection{The capital market}

The variables representing the capital market of the financial market were the $R / \$$ exchange rate, the real effective exchange rate and the balance on the financial account. These variables are in line with those identified by Kaminsky and Schmukler (2001), and at this stage these variables represent the capital market of South Africa. All three variables and the dependent variable were I(1) and cointegration was present; therefore the variables were used on the levels.

The $R / \$$ exchange rate variable and the real effective exchange rate variable were logarithmically adjusted. All three variables were statistically significant (at a $95 \%$ confidence level) and showed a positive relationship with the coincident indicator. Heteroscedasticity and autocorrelation were present and the standard errors were adjusted with Newey-West. The best lag structure was chosen according to the Schwarz information criterion (SIC).

The adjusted R-squared implies that $62 \%$ of the variation in the coincident indicator is due to the explanatory variables.

TABLE 3: Regression results for the capital component

\begin{tabular}{lcccc}
\hline \multicolumn{2}{l}{$\begin{array}{l}\text { Dependent Variable: COIN } \\
\text { Newey-West HAC Standard Errors }\end{array}$} & Covariance (lag truncation=3) & & \\
\multicolumn{1}{c}{ Variable } & Coefficient & Std. Error & t-Statistic & Prob. \\
\hline C & -925.5234 & 303.3622 & -3.050885 & 0.0038 \\
LOG(EXCH(-1)) & 79.06439 & 19.94080 & 3.964955 & 0.0003 \\
LOG(REER(-1)) & 192.1805 & 58.03554 & 3.311427 & 0.0018 \\
BFAC & 0.000868 & $9.75 \varepsilon-05$ & 8.903234 & 0.0000 \\
& & & & \\
R-squared & 0.645856 & & & \\
Adjusted R-squared & 0.622247 & & & \\
\hline
\end{tabular}

Source: Results from Eviews 
FIGURE 2: Capital component of the financial indicator

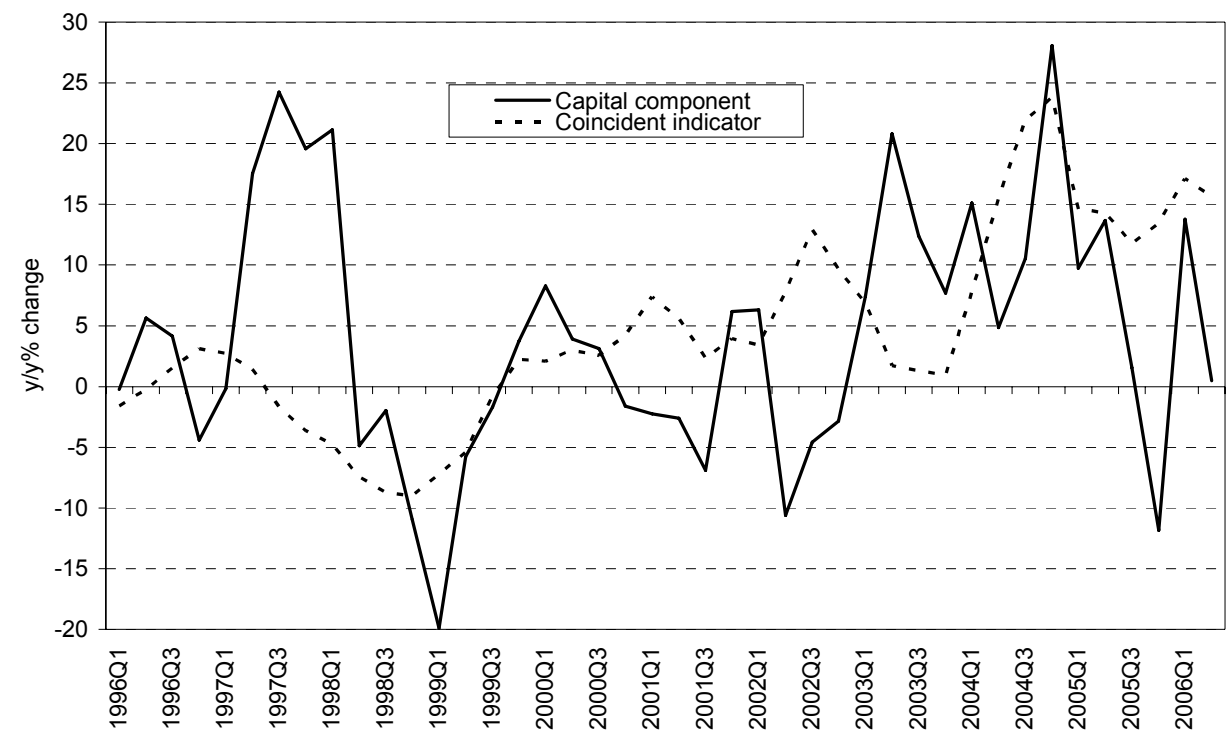

Source: Results from regression model in Eviews

FIGURE 2 shows the estimate from the regression analysis - the capital component. The capital component is very volatile: sometimes the capital component leads, while at other times the coincident indicator leads. This is confirmed by the Granger causality test, which indicated a two-way flow between these two variables.

\subsubsection{The domestic financial sector component}

The previous two components, the equity market and capital market components capture international aspects of the financial market. The domestic component aims to capture the domestic financial sector. The variable used to obtain the domestic component was the real interest rate spread ( 10 -year government bond yield and the three-month BA rate), while the $M 3$ variable represented credit. These variables are in line with those identified by Kaminsky and Schmukler (2001). The order of integration of the variables was different and therefore the differenced values were used in some cases. Both independent variables were statistically significant (at a 95\% confidence level) and showed a positive relationship with the coincident indicator. Heteroscedasticity was not present, but autocorrelation was and the standard errors were adjusted with Newey-West. The best lag structure was chosen according to the Schwarz information criterion (SIC). The adjusted R-squared implies that only $37 \%$ of the variation in the coincident indicator is due to the explanatory variables. 
TABLE 4: Regression results for the domestic financial sector component

\begin{tabular}{|c|c|c|c|c|}
\hline \multirow{2}{*}{\multicolumn{5}{|c|}{$\begin{array}{l}\text { Dependent Variable: } D(C O I N) \\
\text { White Heteroscedasticity-Consistent Standard Errors \& Covariance }\end{array}$}} \\
\hline & & & & \\
\hline Variable & Coefficient & Std. Error & t-Statistic & Prob. \\
\hline C & 2.403791 & 0.914697 & 2.627963 & 0.0117 \\
\hline$D(M 3(-1))$ & $7.05 \varepsilon-05$ & $2.09 \varepsilon-05$ & 3.368381 & 0.0016 \\
\hline $\operatorname{SPREAD}(-1)-\operatorname{INFL}(-1)$ & 0.390069 & 0.093172 & 4.186573 & 0.0001 \\
\hline R-squared & 0.398436 & & & \\
\hline Adjusted R-squared & 0.371700 & & & \\
\hline
\end{tabular}

Source: Results from Eviews

FIGURE 3: Domestic component of the financial indicator

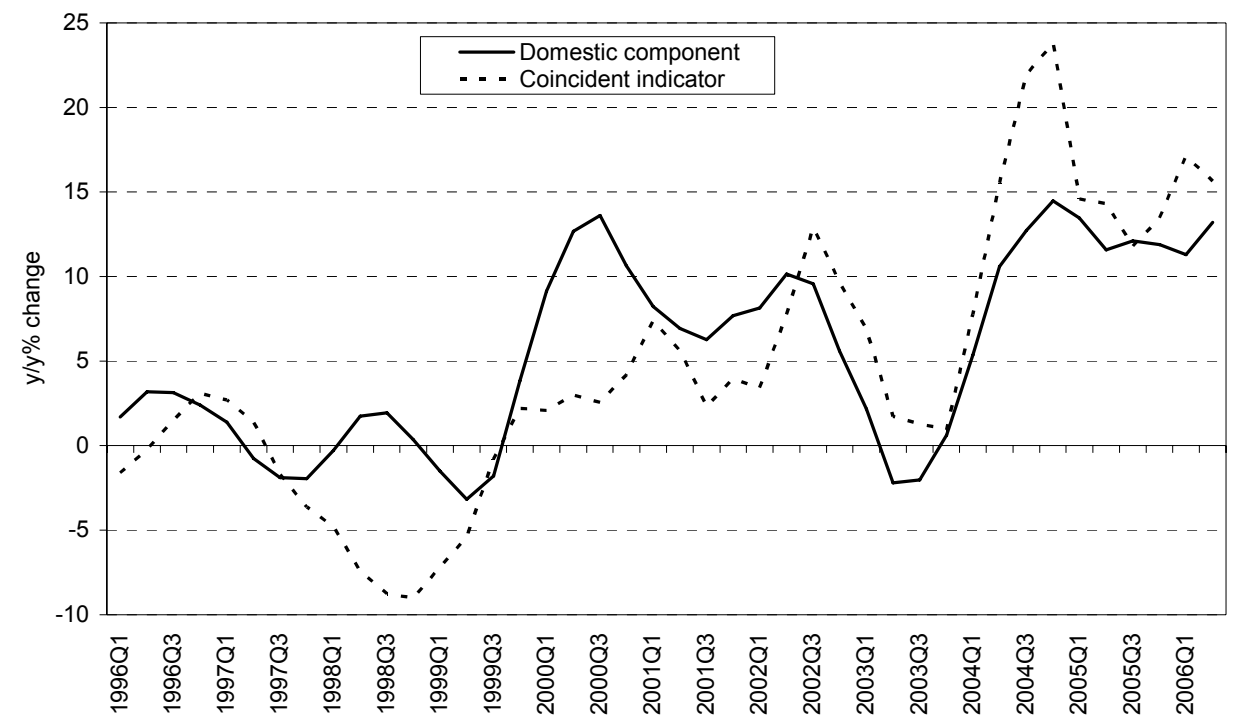

Source: Results from regression model in Eviews

FIGURE 3 indicates a leading relationship between the domestic component and the coincident indicator in some periods. The Granger causality test confirmed this with a strong one-way flow of causality from the domestic component to the coincident indicator.

\subsection{The composite financial indicator for South Africa}

The previous section did the groundwork for the construction of the financial indicator for South Africa. Each component of the financial market was derived by using simple regression analysis. The variables used followed those suggested by Kaminsky and Schmukler in 2001. Each 
component was compared to the coincident indicator, the variable representing the current business cycle. The equity and domestic component had a leading relationship with the coincident indicator. The capital component had a bi-lateral relationship with the coincident indicator, signifying a two-way flow between the two variables.

These three estimated components will now be used to construct a composite financial indicator in South Africa. All three components will be explanatory variables where the coincident indicator is a dependent variable. The estimate from this regression will represent the financial indicator for South Africa.

All three components and the dependent variable were I(1) and cointegration was present; therefore the variables were used on the levels. The cointegration test was done with a trend assumption, because all the ADF tests indicated a significant trend (at a $94 \%$ confidence level).

All three variables were statistically significant (at a $95 \%$ confidence level). Heteroscedasticity and autocorrelation were present and the standard errors were adjusted with Newey-West. The best lag structure was chosen according to the Schwarz information criterion (SIC).

TABLE 5: Regression results for the composite financial indicator

\begin{tabular}{lcccc}
\hline $\begin{array}{l}\text { Dependent Variable: COIN } \\
\text { Newey-West HAC Standard Errors \& Covariance }\end{array}$ & (lag truncation=3) & & \\
\multicolumn{1}{c}{ Variable } & Coefficient & Std. Error & t-Statistic & Prob. \\
\hline C & 29.04470 & 18.79900 & 1.545013 & 0.1306 \\
CAPITALF(-3) & 0.256380 & 0.107508 & 2.384743 & 0.0222 \\
DOMESTICF(-2) & 1.401742 & 0.103756 & 13.50992 & 0.0000 \\
EPUITYF(-4) & -0.925236 & 0.204915 & -4.515223 & 0.0001 \\
& & & & \\
R-squared & 0.923361 & & & \\
Adjusted R-squared & 0.917310 & & & \\
\hline
\end{tabular}

Source: Results from Eviews 


\section{FIGURE 4: Coincident indicator vs. the financial indicator}

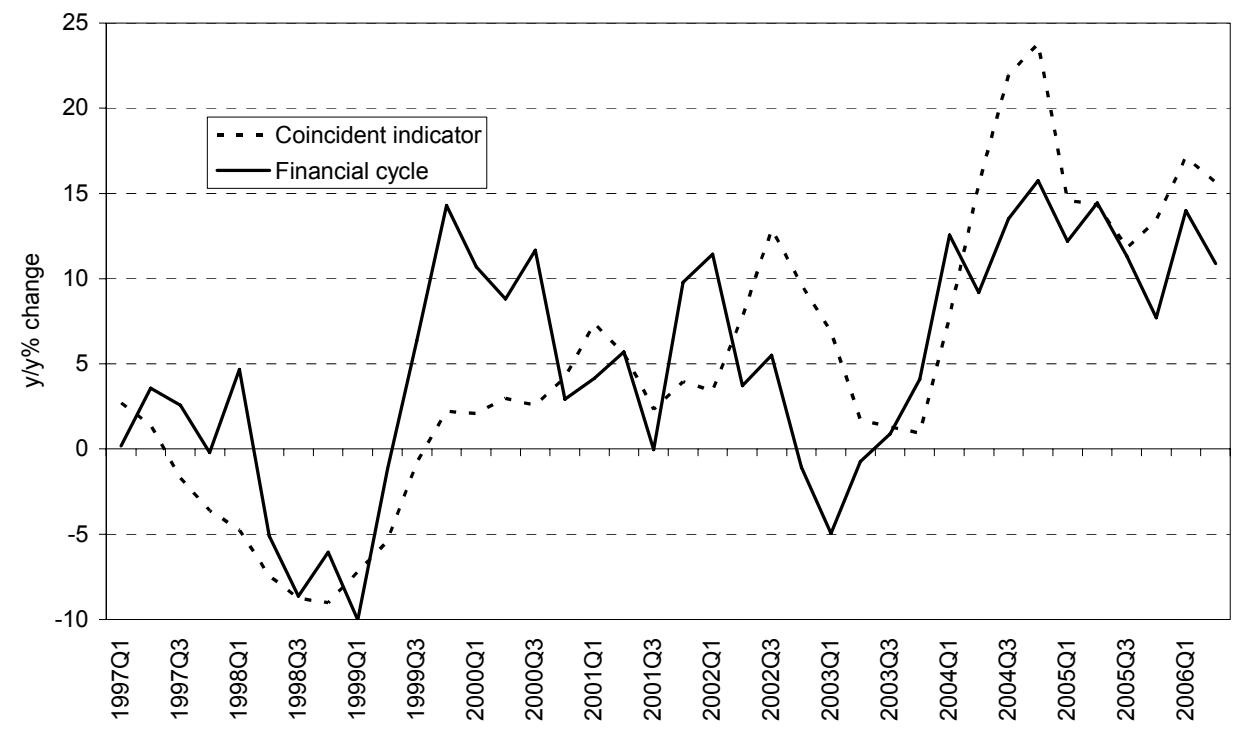

Source: Results from regression model in Eviews

Most of the time the financial indicator leads the coincident indicator, but towards the end of the sample period it seems as if the coincident indicator is leading the financial indicator. The lead range is between one quarter to three quarters. This is especially clear from 2000-2004 in FIGURE 4.

The Granger causality test confirms a two-way flow of causality. In FIGURE $\mathbf{5}$ the three-period moving average of the coincident indicator and the financial indicator is shown. In this figure the financial indicator is leading the turning points in the coincident indicator, and towards the end of the sample period they coincide. The financial indicator is likely to always lead the coincident indicator, because the coincident indicator is released on a quarterly basis, with a time lag, and the variables used to construct the financial indicator are mostly released on a monthly basis. This implies that the data for the financial indicator is more frequently available and therefore the financial indicator could be used as a leading indicator. 
FIGURE 5: Three-period moving average: Coincident indicator vs. the financial indicator

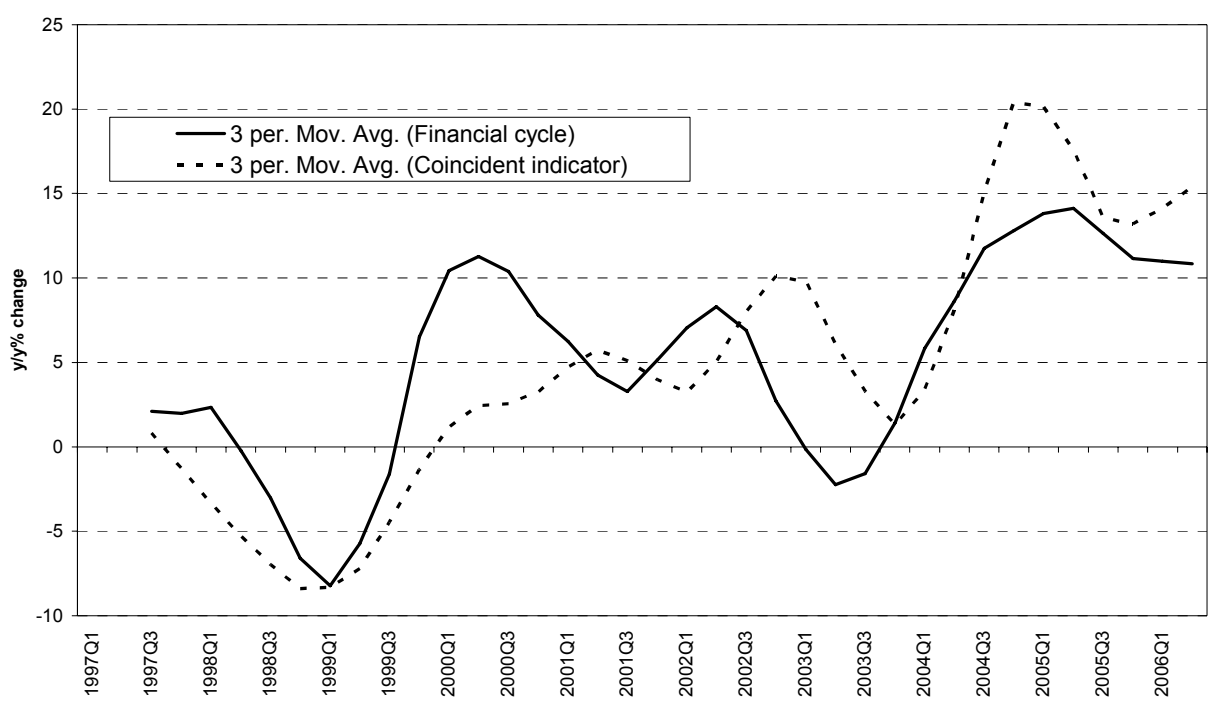

Source: Results and own calculation

\section{FIGURE 6: Out of sample performance of the financial indicator}

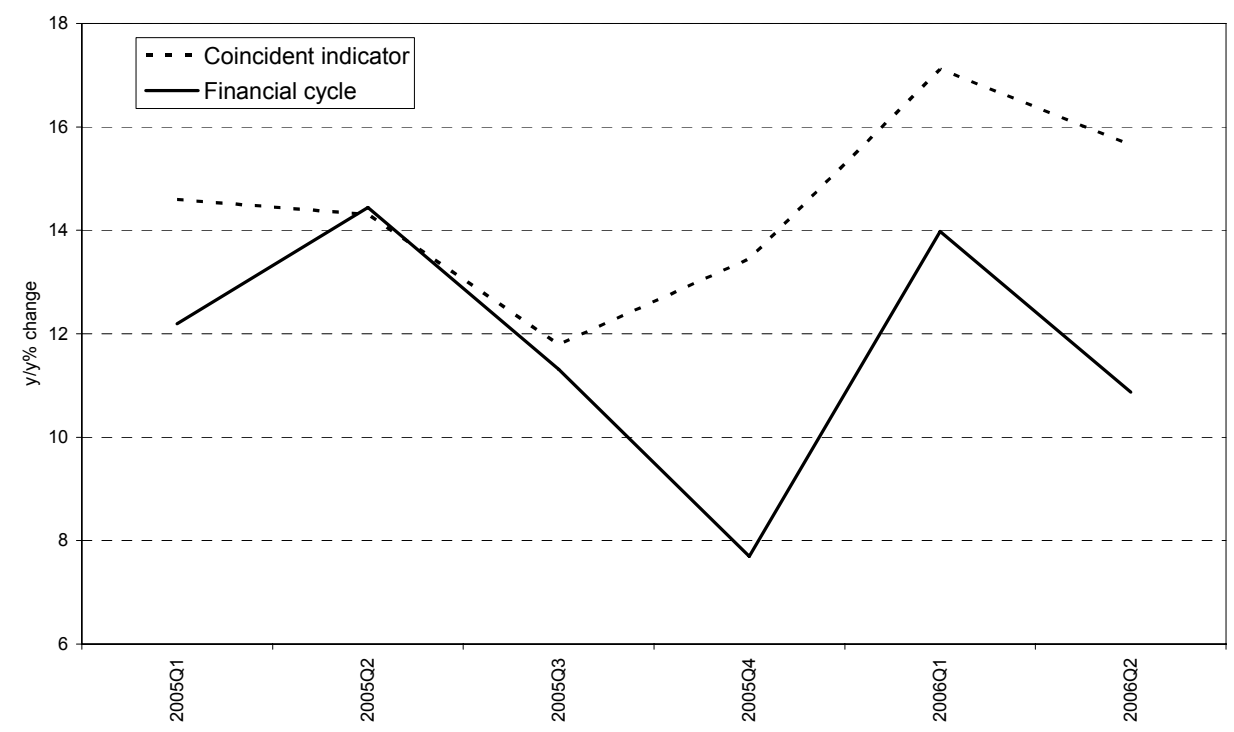

Source: Results and own calculation

The performance of the financial indicator out of sample can be seen in FIGURE 6. The financial indicator is able to predict the turning points in the coincident indicator. 
As mentioned earlier, because of the higher frequency data available for the financial indicator, this indicator may be able to lead turning points in the business cycle.

\section{CONCLUSION}

In this paper a financial indicator for South Africa was constructed which leads the business cycle. The significance of this indicator is that it takes into account three major components of the financial market in order to form a financial indicator. It differs from the business cycle in the sense that only financial indicators are used. These indicators are available on a more frequent basis than the indicators used for the business cycle and therefore they can lead turning points in the business cycle.

A brief discussion was given on the measurement of business cycles as well as measurement of the business cycle in South Africa because the coincident indicator was used in the analysis to construct a financial indicator.

The progress of deregulation and the components of financial liberalisation were discussed in order to emphasise the importance of the financial market in the real economy. Financial liberalisation took place in the mid-1970s for the G-7 economies; emerging market economies followed, but a few stumbling blocks prevented the process from reaching completion. South Africa liberalised in the early 1990s, following the political and social reforms in 1994.

Given the growing importance of financial markets, it would be useful to construct a financial indicator for South Africa that incorporated all major components of the financial market. These components were the capital market, the equity market and the domestic financial sector. A composite index was constructed consisting of these three components. The proxies for the equity market were the JSE all-share index and net equity flows; for the capital market they were the balance on the financial account, the real effective exchange rate and the $R / \$$ exchange rate; and for the domestic financial sector the proxies were the real interest rate spread and $M 3$. After each component was estimated with ordinary least squares, these estimates were used to construct a composite financial indicator. It was found that it was a sufficient leading indicator for the business cycle in South Africa in the sense that it leads turning points the business cycle by at least 1 period. This is a new type of leading indicator for South Africa: it consists of financial sector components only, with no real sector components being used. Since financial sector data is more frequently available than real sector data and since the financial indicator leads turning points in the business cycle, this indicator could serve well in making informed business decisions.

For further research it might be useful to do a comparative study between emerging market countries. This financial indicator can also be refined into a more complex indicator using a method similar to the construction of the business cycle indicators of the South African Reserve Bank. 


\section{REFERENCES}

Calvo, G. \& Mendoza, E. (2000). Capital Market Crises and Economic Collapse in Emerging Markets: An informational-frictions approach. American Economic Review, 90(2), pp. 59-64.

Das, D.K. (2003). Emerging Market Economies: Financial Liberalisation Endeavors and their Impact. Unpublished: Canada.

Edwards, S., Biscarri, J.G. \& De Gracia, F.P. (2003). Stock Market Cycles, Financial Liberalisation and Volatility. National Bureau of Economic Research (Working paper 9817).

Gabisch, G. \& Lorenz, H. (1989). Business Cycle Theory: A Survey of Methods and Concepts, $2^{\text {nd }}$ edition. Germany: Springer-Verlag.

Kaminsky, G.L. \& Reinhart, C. (1999). The Twin Crises: The Causes of Banking and Balance of Payments Problems. American Economic Review, 89(3), pp. 473-500.

Kaminsky, G.L. \& Schmukler, S.L. (2001). On Booms and Crashes: Financial Liberalisation and Stock Market Cycles. World Bank: Policy Working Paper No. 2565, Washington DC.

Kaminsky, G.L. \& Schmukler, S.L. (2002). Short-run Pain, Long-term Gain: The Effects of Financial Liberalisation. Paper presented at the joint conference between the World Bank and George Washington University on Financial Globalisation: A Blessing or a Curse? Held on May 30-31, 2002, in Washington DC.

Klein, P.A. (1997). Recent US Work in Cyclical Indicators: An assessment. IFO Institute for Economic Research, Discussion paper no.49.

Pretorius, W.S., Venter, J.C. \& Weideman, P.J. (1999). Business Cycles in South Africa during the Period 1993-1997. South African Reserve Bank Quarterly Bulletin, March 1999.

Pretorius, W.S. \& Venter, J.C. (2001). A Note on the Business Cycle in South Africa during the Period from 1997-1999. South African Reserve Bank Quarterly Bulletin, September 2001.

Pretorius, W.S. \& Venter, J.C. (2004). Note on the Revision of Composite Leading and Coincident Business Cycle Indicators. South African Reserve Bank Quarterly Bulletin, March 2004.

Schwert, G.W. (1989). Business Cycles, Financial Crises and Stock Volatility. Carnegie-Rochester Conference Series on Public Policy, New York. 31, pp. 83-125.

Sherman, H.J. \& Kolk, D.X. (1996). Business cycles and forecasting. New York: Harper Collins College Publishers.

Republic of South Africa (RSA). South African Reserve Bank Quarterly Bulletin (March 2004). South African Reserve Bank: Pretoria.

Stals, C.L. (2002). The Economic Impact of Globalisation in the Context of the South African Region. Aambeeld, RAU July 2002. 
